\section{The Gas Referees and the Gas Industry}

GCIENCE and industry are dependent for $S$ much of their progress on the existence and authority of master men to whom the less experienced and less endowed may turn for direction and advice. During periods of stress or emergency their value is readily recognised and their services eagerly sought; in normal times there is a danger that their existence may be forgotten because of their very modesty and the quiet and unobtrusive manner in which they work; but their presence in the background as an ultimate source of effective authority is essential. Those whom the community choose as such counsellors are men of wide experience, of outstanding ability : men whose word is accepted without question. Often they have retired from the routine of daily duty and, unencumbered by masses of detail, they are thus better able to see a problem in its entirety and to set it in the frame of their whole experience.

In the light of these considerations, it is particularly regrettable that any community which in the past has been fortunate enough to possess such a source of counsel, should now contemplate its abandonment. The gas industry in Great Britain is a body which, for nearly seventy years, has possessed a source of inspiration and advice in the eminent men who have held the positions of Gas Referees and Chief Gas Examiner. Names such as those of Rücker, Tyndall and Harcourt, Williamson and Rayleigh, as past holders of these positions, coupled with those of the present gas referees-C. V. Boys; W. J. A. Butterfield, and J. S. Haldane-and the present chief gas examiner, Sir Richard Glazebrook, are in themselves evidence of the type of man who has given his services unsparingly in the interests of the gas industry.

The duties of the gas referees are to prescribe the places, times, apparatus and methods by which the gas is to be tested, and to determine if these tests are being carried out; they also decide the methods by which the apparatus employed is to be tested. Gas examiners, who have to make the tests, are appointed by the local authorities. The referees issue a general specification applicable to all' undertakings and, where necessary, special specifications for any particular supply company. They also issue full and detailed descriptions of the apparatus to be used, much of which is the invention of Dr. C. V. Boys himself, and of the method of using this. All this is scientific work involving a knowledge of test methods and of the conditions of manufacture of gas.

The gas companies can appeal on certain points, and the chief gas examiner has to hear and decide the appeals. They can appeal against the specification, but we believe that there never has been such an appeal; nevertheless they value this privilege, and object to the Board of Trade, which is to make the specifications, also hearing appeals against them. They can also appeal against any particular test, and though usually the decision is easy, occa. sionally abstruse scientific questions are involved.

Such, in brief, are the chief duties of the gas * referees and the chief gas examiner, and under their direction the routine business of gas testing has been ably conducted; but their services to the gas industry have been greater than any which could be prescribed by an Act of Parliament. Their real value and their real function have been those of counsellors. In the Gas Undertakings Bill which was recently introduced to the House of Commons, the proposal is made that the offices of Chief Gas Examiner and of Gas Referees should be discharged by the Board of Trade. There can be no doubt that the routine of gas testing, the collection of data relating to the gas industry, and similar routine work, can be efficiently and competently carried out by the civil servants to whom these duties may be delegated by the Board of Trade; but it is impossible that such civil ser. vants, however efficient, can achieve that which has arisen from the eminence of the men who have previously been responsible for this work. The loss which the gas industry would incur by this change is beyond all computation.

It may be suggested, on behalf of the proposed change, that the replacement of the present holders of the offices would be no easy matter. Undoubtedly this is true, for eminent men are always scarce, but amongst present occupants of chairs of physics and chemistry at the universities of Great Britain there are men of outstanding merit who will, by the passage of years, be compelled to retire from active participation in academic work, and would be willing to place at the disposal of the gas industry the knowledge arising from their experience.

It seems incredible that the gas industry in Great Britain should wish deliberately to divorce itself from association with some of the ablest scientific men of the day. Must it not be that the change has been proposed without full consideration of the inevitable consequences? 